\title{
La prisión del «emperador de los mexicanos»
}

\section{The Prison of the «Mexican's Emperor»}

\section{Arnulfo Herrera}

https://orcid.org/0000-0002-8870-9684

Instituto de Investigaciones Estéticas, UNAM

MÉXICO

arnulfoh@unam.mx

[Hipogrifo, (issn: 2328-1308), 9.2, 2021, pp. 309-316]

Recibido: 10-02-2021 / Aceptado: 10-03-2021

DOI: http://dx.doi.org/10.13035/H.2021.09.02.23

Resumen. El irlandés Guillén de Lampart llegó a México en 1640, fue aprehendido en 1642 y quemado vivo por la Inquisición en 1659. Su dilatado proceso tiene muchas incógnitas, porque inicialmente se le detuvo por cargos de brujería, con acusaciones de judaizante y mago judiciario, pero durante su breve fuga de tres días escribió un panfleto que pegó en varias partes de la ciudad y luego, en el «Desagravio...» que lo obligaron a escribir, descubrió la inquina de los inquisidores confabulados con el arzobispo Juan de Mañozca. La megalomanía de Lampart impide descifrar en sus escritos si realmente era un espía del conde-duque de Olivares, si la fantástica fuga de las cárceles inquisitoriales tuvo alguna relación con sus alucinaciones o si solamente era un intelectual enloquecido que invitó a la sedición y se declaró «emperador de los mexicanos».

Palabras clave. Nueva España; Inquisición; Guillén de Lampart.

Abstract. The Irish Guillén de Lampart arrived in Mexico in 1640, was apprehended in 1642 and burned alive by the Inquisition in 1659. His lengthy trial has many unknowns. Initially, he was arrested on charges of witchcraft, with accusations of Judaizer and Judicial Magician. During his brief three-day escape he wrote a pamphlet that he posted in various parts of the city. Later, in the «Reparation...» that he was forced to write, he discovered the anger of the inquisitors in cahoots with Archbishop Juan de Mañozca. The megalomaniac features of Lampart's writings make it difficult to decipher whether he was really a spy in the service of the 
Count-Duke of Olivares, or whether the fantastic escape from the inquisitorial prisons had any relation to his hallucinations, or whether he was just a maddened intellectual who invited the sedition and declared himself «emperor of the Mexicans».

Keywords. New Spain; Inquisition; Guillén de Lampart.

Guillén de Lampart arribó a Veracruz el 24 de junio de 1640 y fue quemado vivo por «hereje pertinaz» el 19 de noviembre de 1659. De los diecinueve años y cinco meses que estuvo en México, diecisiete años y un mes, los pasó recluido en las cárceles secretas de la Inquisición. Aunque el expediente de su causa se conserva casi íntegro y se ha logrado reunir una documentación muy amplia en torno a su historia, muchas incógnitas permanecen aún latentes y no se han llegado a conocer los verdaderos motivos que tuvo el Santo Oficio para actuar con una saña desmesurada e inusual. Lo primero que salta a la vista es la prolongada dilación en un proceso de dos etapas separadas apenas por los tres días que anduvo prófugo luego de escabullirse del calabozo en compañía de Diego Pinto Bravo, su compañero de celda. Los largos intervalos en que se desarrollaron las diligencias del caso parecen estar ligados al interés de los inquisidores por mantenerlo incomunicado y a la vez hacerse de motivos contundentes para emitir una condena que entrañase la pena capital.

La explicación más directa que podría formularse proviene de una conjetura: Guillén de Lampart venía en el cortejo del marqués de Villena, el décimo séptimo virrey de la Nueva España y, una vez instalado el gobierno, no recibió ninguna prebenda, merced o encargo público, lo cual significa que no formaba parte de aquella corte y, por tanto, debió sustentarse con un modesto empleo de profesor de gramática latina que desempeñó en la casa del escribano mayor del Cabildo de la Ciudad de México, Fernando Alonso Carrillo Altamirano. No existen documentos que indiquen las causas por la cuales este irlandés se embarcó para América casi como polizón y solamente quedan las razones que él mismo dio a los inquisidores en el Cristiano desagravio..., un opúsculo elaborado bajo coerción en febrero de 1651 donde trató de justificar su reciente fuga y las ofensas inferidas en un libelo a los miembros del Santo Tribunal, así como explicar las motivaciones de sus actos y construir una apología pro vita sua. Dice Guillén:

a seis de enero del año de treinta y nueve, llegó aviso a su majestad, despachado de esta Nueva España por el señor marqués de Cadereyta ${ }^{2}$, con siniestro informe, intimando que había en esta pacífica y leal ciudad adversos tumultuantes. Y tanto perturbó con esto al real ánimo, que se entendió que ya el reino había prevaricado. Mandome, por órdenes reclusas del señor conde-duque ${ }^{3}$ y secretas instrucciones,

1. No hay rastros de las numerosas mercedes que -según dijo en uno de sus escritos- le habían hecho poco antes de su viaje a América. Las recompensas que recibió por sus servicios están mencionadas en el Cristiano desagravio, pp. 69-70.

2. Lope Díez de Aux de Armendáriz, marqués de Cadereita, décimo sexto virrey de la Nueva España entre septiembre de 1635 y agosto de 1640 .

3. El conde-duque de Olivares, privado de Felipe IV. 
que pasara a estos reinos, con todo recato y política disimulación, para que, si habían las disonancias tan vertidas, pidiese las órdenes remitidas al contador mayor de cuentas y regidor de México, Cristóbal de Molina, y la duplicada de ellas al escribano mayor del cabildo y ayuntamiento de esta ciudad, don Fernando Carrillo, para que presentara ante esta Real Audiencia los despachos y, no habiendo nada, se remitiesen con el recato recomendado, como se hizo... ${ }^{4}$

Como sus órdenes eran «reclusas» y traía «secretas instrucciones», seguramente don Guillén de Lampart no pudo mostrar ningún documento a los inquisidores, ni dar pruebas de la misión confidencial que le habían encargado desde las más altas esferas del gobierno hispánico. Sin embargo -aclara el propio Guillén- de haber encontrado «las disonancias» esperadas en la Nueva España, tenía que entenderse con el regidor Cristóbal de Molina o con el escribano del cabildo, Fernando Carrillo, a fin de obtener su intercesión ante la Real Audiencia para aprehender a los prevaricadores. Tal vez así se puede explicar el hecho de que Guillén, sin aparentemente conocer a nadie en la Ciudad de México, estuviera viviendo en la casa del escribano Carrillo y percibiera de él un salario a cambio de enseñar latín a sus hijos. Tanto si la misión que llevaba a cabo el irlandés «con todo recato y política simulación» era verdadera, como si esta fuera una falsedad, lo cierto es que parece más bien una traza de sus afanes de aventurero o las megalomaníacas fantasías de un auténtico enfermo mental.

El caso es que, por sus diligencias, Guillén de Lampart dice haber sido recompensado y, mientras esperaba el momento de volver a España para gozar de los bienes concedidos por sus servicios, la noche del 26 de octubre de 1642 fue aprehendido por los porquerones de la Inquisición y llevado a las mazmorras perpetuas sin que le notificaran las acusaciones de que era objeto. Guillén declaró:

Conocida mi fidelidad, celo, capacidad y vigilancia, guardando en todo aquel real sigilo inviolable, proveyendo su majestad, que Dios guarde, en apoyo y confirmación de mis proposiciones discernidas y avisos, sin discrepancia alguna, como parece por los originales allá, en su real cámara, y los afectos acá deliberados, y entonces me avisó el señor conde-duque de cómo se me había hecho merced de título de marqués y que tenía guardado el decreto real. Y esperando ocasión para pasar a España, a gozar de los favores en premio de mis desvelos y méritos de mis antepasados, fui frustrado y preso por esta Inquisición de México... 5

Y aunque más tarde «conoció» las imputaciones que se le hacían, encontró que las denuncias habían sido fabricadas con testigos falsos; se le apresaba por haber dado peyote a un indio ciego con el propósito de que éste adivinara si Guillén habría de convertirse en virrey ${ }^{6}$, por haber intentado curarle la impotencia a un judío portu-

4. Guillén, Cristiano desagravio, p. 70.

5. Guillén, Cristiano desagravio, p. 71.

6. En la página 83 del Cristiano desagravio detalla los pormenores del incidente: «que había ocho meses poco más o menos antes de mi prisión, que estando con un pleito contra cierta justicia, viviendo yo en las casas de cabildo, le dije un día que bebiese dicha yerba para saber (dice) si se había muerto una dama en España y si me venía algún oficio; y que le mandé pedir dinero, la compró, se lo molí y se lo di a beber; y estando recogido en una sala de noche, oyendo que yo había salido, lo derramó y no lo bebió, 
gués de nombre Juan Méndez Villaviciosa mediante una invocación mental dirigida a un personaje de las tinieblas y por haber convidado para merendar a un sujeto de nombre Francisco del Corral, a quien le sirvió en vajilla de oro que tenía grabados caracteres indescifrables unos «manjares exquisitos que no se hallan en estos reinos». Eran tres cargos que Guillén desestimó y tildó de absurdos, para afirmar que la verdadera causa de su encarcelamiento se debía a motivos políticos que cubrían la ambición pecuniaria de los inquisidores:

Es verdad que cuando el dicho Santo Oficio de México hizo la prisión grande de portugueses, a trece de junio del año de cuarenta y dos, escribí a su majestad, que Dios guarde, conforme consta por los originales en su real secreta, y remitidas por diversas vías, muchas duplicadas de este pliego: una fue por vía de esta Inquisición de México, que llevó y entregó Sebastián de Almeyda, en el cual había una cláusula por vía de recuerdo que decía cómo estaban presos dichos portugueses por el delito de judaísmo, y era la gente más poderosa del reino que sustentaba el comercio; que si era verdad que estaban convencidos del delito, fuese servido su majestad mandar se despachasen luego, porque no se consumiera el tesoro confiscado con pretexto de retardados, pues era necesario para los socorros reales; y si no lo eran, seguía el mismo inconveniente, pues el comercio estaba exhausto en ellos y los derechos reales atenuados, así que de cualquier camino parecía conveniente fuesen despachados. Y aunque en mi querella dije que este era el motivo oculto porque dicha Inquisición me prendió, no era el motivo que se me dio de mi prisión?

El caso es que, luego de ocho años y dos meses sin que su proceso tuviese visos de desahogarse, y sin encontrar razón alguna para la demora puesto que a él no le habían confiscado bienes como a los portugueses judaizantes cuyos procesos se dilataron para consumir sus fortunas, y a pesar de ello se habían resuelto en los autos de fe de 1646, 1647, 1648 y en el magno auto general celebrado el 11 de abril de 1649, luego de todo ese tiempo, Guillén se desesperó y se fugó de la prisión en la noche de la Navidad de 1650. No fue un acto de menor importancia y debió causar un impacto muy grande en la sociedad novohispana porque escapar de las cárceles inquisitoriales requería de habilidades poco comunes, por no decir extraordinarias. El cronista Gregorio Martín de Guijo registró algunos pormenores del escándalo y en su crónica proporciona los datos más sobresalientes:

Lunes 26 de diciembre, corrió voz por la ciudad de haberse huido de las cárceles secretas del santo Oficio de la inquisición de este reino, don Guillén de Lombardo alias de Guzmán y su propio nombre Guillermo Lampart, de nación irlandés, y Diego Pinto Bravo, de oficio herrador, y el martes 27 se leyeron edictos públicos en todas las iglesias a la hora de la misa mayor, en que se daba noticia de cómo la Noche Buena habían roto diferentes rejas de fierro y se habían salido, dejando fijados edictos o libelos infamatorios contra los inquisidores y el señor arzobispo; y los llamaban y mandaban todas y cualesquier personas que de ellos supiesen

pero que al día siguiente me dijo que sí, y lo que le vino a la memoria por tenerme (dice) miedo. Y en otra forma de este cargo dice la bebió y estaba en vela toda la noche encomendándose a Dios, y no vio más que una penosa noche, pero que me dijo a mí lo que se le vino».

7. Guillén, Cristiano desagravio, pp. 78-79. 
los manifestasen, so graves penas pecuniarias y corporales, y dieron señas de los rostros, cuerpos, talles y la edad, y habiéndose leído los edictos, acudió al tribunal un vecino de esta ciudad, de oficio carrocero, que vive en la calle de los Donceles a espaldas del Colegio de Santa Ana, y manifestó que había oído el edicto y por las señas de las personas referidas tenía en un sótano de su casa al dicho Guillén, que se había recogido en ella sin conocerle él, diciéndole que había cogido a una mujer con un hombre, y que hasta que sosegase el rumor de la muerte de él, le tuviese oculto en su casa, y así lo manifestaba; envió el tribunal gente y lo volvieron a las cárceles; dio un pliego de cartas al virrey escribiéndole muy largo y dándole cuenta de las ocupaciones de los inquisidores con descrédito de sus personas, que visto por el virrey, envió a llamar a los inquisidores, y a uno de ellos le dio la carta y que en su presencia leyese, y habiéndosela leído en parte, oyendo tan graves cosas, les dijo que las llevasen y se fuesen, como lo hicieron, y luego supieron la fuga y despacharon los edictos referidos ${ }^{8}$.

Una semana después, ya con Guillén reaprehendido, los inquisidores promulgaron el edicto para recoger los libelos e impedir cualquier modo de transmisión que pudieran hacer aquellos que los hubieran leído:

Edictos de la Inquisición. Dicho día 1. de enero domingo, se leyeron por mandado del tribunal del santo Oficio edictos, pidiendo que dentro de seis horas todas y cualesquier personas que hubiesen quitado de las esquinas de las calles de Tacuba y Donceles, unos libelos infamatorios que de su letra fijó don Guillén de Lombardo, contra los inquisidores y señor arzobispo; o los hubiese leído, o trasladado, o supiese de ellos, los exhiban, pena de excomunión mayor, late sententiae, sin tildarlos ni romperlos por sí, o en consejo de otra persona, so la misma pena ${ }^{9}$.

Está claro que a los inquisidores les afectaba sobremanera el contenido del libelo y la relación de la industria que Guillén había empleado para salir de la cárcel. Sus invocaciones y sus quejas tenían resonancias peligrosas para los feligreses y muy posiblemente para las autoridades civiles y eclesiásticas. En la cabeza del pasquín se leía Pregón de los justos juicios de Dios, que castigue a quien lo quitare y pedía una justicia que venía reclamando desde que inició su encarcelamiento:

Yo don Guillén Lombardo, revocando como revoco el emplazamiento que hice de mis agravios ante el justo tribunal de Dios, protesto en su presencia soberana, en la de los ángeles y hombres, que no emplacé a los dichos mis contrarios, siendo tan inicuos, para que Dios nuestro señor les castigara en la otra vida, sino para su enmienda de ellos en la presente, por sus horrores cometidos con capa del secreto y religión. Y por que venga a noticia universal de todos, digo que yo emplacé el año de cuarenta y tres a Domingo de Argos defunto, inquisidor que fue de México, según consta por escrito en dicho tribunal. Y otra vez en mis descargos emplacé a todos los demás que son y fueron cómplices y causas de mis agravios y aleve muerte, como consta de mi proceso de mi letra y mano fecho en el mes de febrero del año de cuarenta y nueve ${ }^{10}$. 
Guillén no solo se quejaba de los inquisidores Francisco de Estrada, Juan Sáenz de Mañozca, Bernabé de la Higuera y los secretarios Tomás López de Arendún y Eugenio de Sarabia, sino que acusaba directamente al arzobispo Juan de Mañozca que había rechazado al visitador que llegaba de Chiapas:

Y habiendo sido uno de ellos y principal autor el arzobispo de México don Juan de Mañozca como visitador que fue de dicha inquisición, no solo ocultó los dolos abominables de los dichos inquisidores, sino que cometió con ellos los mismos horrores como está patente. Y llamó algunos presos el mes de noviembre, diciembre y antes para hacerse el Auto General y atroz, estando oprimidos en poder de sus aleves enemigos, que eran jueces y partes, oprimiendo a los míseros y impidiendo que no declarasen los fraudes, atrocidades, desesperaciones, felonías apostasías, latrocinios y más delitos de los dichos inquisidores. Sirviendo dicha visita solo para mayor aumento de las ofensas contra Dios y engaños para el mundo, cometidos con pretexto del secreto y religión. Y porque los dichos facinerosos del secreto sabían como consta del proceso aleve que contra mí fraguaron y por los cuadernos míos, que no solo defendía yo la pureza de nuestra santa fe católica con la vida, sino que increpaba juntamente sus iniquidades, no me llamó el dicho arzobispo, receloso de que a ellos no les condenara en las penas de muerte y herejías que habían incurrido y están notorias en dichos mis escritos, ni a él le redarguyera por inicuo, pues no guardaba amago de justicia, ni verdad, sino antes horror opuesto a la divina majestad y humana, urdiendo todos sus atrocidades sin conocimiento de Dios ni temor de sus castigos. Y con este dolo rechazaron la visita del señor obispo de Chiapa ${ }^{11}$.

El problema que Guillén de Lampart parece referir en su libelo no apunta a las injustas acusaciones de judaizante y mago judiciario que lo mantenían inmerso en el proceso, sino a las denuncias que formula contra el empleo interesado de la justicia practicada por el gobierno de la iglesia mexicana. Pero su incapacidad para expresar estas iniquidades sin las grandilocuencias de su megalomanía (tal vez morbosa), lo llevan a la elaboración de imágenes dantescas que no hacen otra cosa que acentuar una posible relación con las fuerzas infernales o, lo que podría ser más probable, el padecimiento de una enfermedad mental: narcisismo esquizoide. No queda claro, sin embargo, por qué razón, a la muerte del arzobispo Juan de Mañozca ocurrida dos semanas antes de que Guillén realizara su espectacular fuga de la prisión, la real justicia procedió de inmediato a confiscar los bienes del prelado y seis días después amaneció muerto Francisco de Olabe, el secretario del arzobispo $^{12}$. Guillén afirmó que su fuga de las cárceles inquisitoriales se debía a una conminación expresa del arzobispo muerto quien se le había aparecido el 12 de diciembre, que fue la misma noche de su muerte:

Por cuya causa ha permitido Dios que dicho arzobispo se me apareciera emplazado como apareció a media noche, doce del mes presente de diciembre de este presente año de cincuenta, en que dijo había fallecido antes de las ocho aquella misma noche. Entró en dicha mi prisión envuelto en llamaradas. Y Diego Pinto, también sin causa inicuamente con muerte oprimido en dicha prisión atroz, que

11. Lampart, «Pregón de los justos juicios de Dios, que castigue a quien lo quitare», s. p.

12. Guijo dio la noticia el 18 de diciembre de 1650. Véase p. 141 
estaba conmigo, quedó sin sentido y como muerto del horror y miedo. Y entre otras cosas (que no se pueden revelar), declaró por justos juicios del cielo lo susodicho, mandándome pregonar al mundo este feroz delito suyo y dellos y lo demás tocante a esto, y que lo presentara todo ante justicia mayor por la primera vía que se me ofreciera sin dilatarlo instante, y por edictos lo divulgara, así como lo hago. Y que él por comisión del cielo vendría a su tiempo y me sacaría, venciendo estorbos sin que pavor alguno me asombrase ${ }^{13}$.

Lampart amplificó esta visión del arzobispo aparecido en llamas con las descripciones de los recursos que le sirvieron para fugarse y que tienen un evidente propósito de amedrantar a los jueces. Luego de relatar que la aparición del prelado muerto lo había llevado a una terrible penitencia llena de mortificaciones corporales, ayunos, desvelos y oraciones, Guillén narró la fantástica historia de su fuga:

... esta noche pedí señal con que viera el mundo cómo Dios me sacó para efectos que su bondad permite. Desgajó en un instante rejas, arranca yerros broncos, dejando abrasadas las maderas. Y con uno de ellos encendido con la calor de su propia mano cortó de mi tarima un retazo en un minuto, pulió vigas que están flamantes sus astillas, hizo escala para que sin temor de impulso caminara, lió mi ropa, descuadernó estorbos de otras rejas y de puertas, porque se viera en todo que pudo más en un instante que la potencia corporal en años. Remito a la vista los originales, que se vean antes que la falaz sombra del secreto los oculte y los desmienta ... Permite todo Dios por su divino acuerdo para que todos caigan en sí y se recelen del furor divino desviándose de la malicia, fraude y tiranía, viviendo bien para morir sin pena: en conformidad de todo así lo he cumplido. Suplicando sean castigados, presos y confiscados los bienes que no son suyos por sus atrocidades hechas contra ambas majestades, como están patentes, convencidos por los contextos en el secreto felionoso encubiertos. Todo sea para honra y gloria de Dios bendito en sus eternos juicios y clemencias santas y extirpación de tan sacrílegos engaños hechos con la sombra de la misma fe ${ }^{14}$.

En algún momento de su efímera libertad, Guillén logró hacer llegar al virrey Luis Enríquez de Guzmán el libelo que andaba pegando en las calles y no sabemos si también le entregó algún documento más, expresamente dedicado a él. Como anotó el cronista Guijo, el virrey conde de Alba de Liste llamó a uno de los inquisidores e hizo que, en su presencia, leyese las acusaciones y se hiciera cargo de los papeles. Consta en el expediente que, más de un año después, en una carta fechada el 31 de diciembre de 1651 y firmada por el rey Felipe IV, venía una severa reprimenda contra el virrey por haber entregado a la Inquisición los papeles de don Guillén de Lampart: "por lo menos pudiérades haber os quedado con copias de los dichos papeles, y para adelante lo tendréis entendido así, en otros casos que se ofrezcan desta calidad» ${ }^{15}$.

13. Lampart, «Pregón de los justos juicios de Dios, que castigue a quien lo quitare», s. p.

14. Lampart, «Pregón de los justos juicios de Dios, que castigue a quien lo quitare», s. p.

15. «Papeles de don Guillén, Colección Conway», p. 155 
A pesar de tantos datos que ofrece la documentación sobre Guillén de Lampart, no es posible explicar muchas cosas, ni siquiera las más importantes de su personalidad y de sus andanzas. ¿Fue realmente un espía del conde-duque de Olivares (caído en desgracia en 1643) o solo era un vagabundo carismático, sabio y loco con delirios de grandeza? ¿Cómo hizo explotar las rejas de su prisión? Los salmos de su Regio Salterio, escritos en folios hechos con las sábanas de su cama, y los demás textos que dejó y le recogieron, permiten ver a un gran escritor cuyo arbitrario encierro lo llevó al desatino, a proclamar la emancipación política de la Nueva España, a declararse «rey de América» y «emperador de los mexicanos». Todo apunta a un enfermo mental que, en las alucinaciones de su injusto aisalmiento y su demorado proceso, mucho antes de que aparecieran las ideas libertarias que desataron la revolución francesa y la independencia de las Trece Colonias, bosquejó con siglo y medio de anticipación la fantasía de un México independiente y la abolición de la esclavitud.

\section{BiBLIOgRAFÍA}

Guijo, Gregorio Martín de, Diario 1648-1664, tomo I, México, Porrúa, 1986.

Guillén, Lombardo de, Cristiano desagravio y retractaciones de don Guillén de Lombardo, ed. Gonzalo Lizardo, Zacatecas, Universidad Autónoma de Zacatecas, 2017.

Guillén de Lampart, «Pregón de los justos juicios de Dios, que castigue a quien lo quitare», en Memoria Política de México, s. p.

«Papeles de don Guillén, Colección Conway», en Gabriel Méndez Plancarte, Don Guillén y su «Regio Salterio». Ms. latino de 1655, México, Bajo el signo de «Ábside», 1948, pp. 154-155. 